This is an electronic reprint of the original article. This reprint may differ from the original in pagination and typographic detail.

Author(s): Morgan, lan; Mansikkamäki, Akseli; Zissimou, Georgia A.; Koutentis, Panayoitis A.; Rouzières, Mathieu; Clérac, Rodolphe; Tuononen, Heikki

Title: Coordination Complexes of a Neutral 1,2,4-Benzotriazinyl Radical Ligand: Synthesis, Molecular and Electronic Structures, and Magnetic Properties

Year: $\quad 2015$

Version:

Please cite the original version:

Morgan, I., Mansikkamäki, A., Zissimou, G. A., Koutentis, P. A., Rouzières, M., Clérac, R., \& Tuononen, H. (2015). Coordination Complexes of a Neutral 1,2,4-Benzotriazinyl Radical Ligand: Synthesis, Molecular and Electronic Structures, and Magnetic Properties. Chemistry: A European Journal, 21(44), 15843-15853.

https://doi.org/10.1002/chem.201501343

All material supplied via JYX is protected by copyright and other intellectual property rights, and duplication or sale of all or part of any of the repository collections is not permitted, except that material may be duplicated by you for your research use or educational purposes in electronic or print form. You must obtain permission for any other use. Electronic or print copies may not be offered, whether for sale or otherwise to anyone who is not an authorised user. 


\title{
Coordination Complexes of a Neutral 1,2,4-Benzotriazinyl Radical Ligand: Synthesis, Molecular and Electronic Structures, and Magnetic Properties
}

\author{
Ian S. Morgan, ${ }^{* a]}$ Akseli Mansikkamäki, ${ }^{[a]}$ Georgia A. Zissimou, ${ }^{[b]}$ Panayiotis A. Koutentis, ${ }^{[b]}$ Mathieu \\ Rouzières, ${ }^{[c, d]}$ Rodolphe Clérac ${ }^{[c, d]}$ and Heikki M. Tuononen* ${ }^{[a]}$
}

\begin{abstract}
A series of $d$-block metal complexes of the recently reported coordinating neutral radical ligand 1-phenyl-3-(pyrid-2-yl)1,4-dihydro-1,2,4-benzotriazin-4-yl (1) was synthesized. The investigated systems contain the benzotriazinyl 1 coordinated to a divalent metal cation, $\mathrm{Mn}^{\prime \prime}, \mathrm{Fe}^{\prime \prime}, \mathrm{Co}^{\prime \prime}$ or $\mathrm{Ni}^{\prime \prime}$, with 1,1,1,5,5,5hexafluoroacetylacetonato (hfac) as the auxiliary ligand of choice. The synthesized complexes were fully characterized by single crystal X-ray diffraction, magnetic susceptibility measurements and electronic structure calculations. The $\mathrm{Mn}(\mathbf{1})(\mathrm{hfac})_{2}$ and $\mathrm{Fe}(\mathbf{1})(\mathrm{hfac})_{2}$ complexes displayed antiferromagnetic coupling between the unpaired electrons on the ligand and the metal cation, whereas the interaction was found to be ferromagnetic in the analogous $\mathrm{Ni}(\mathbf{1})(\mathrm{hfac})_{2}$ complex. The magnetic properties of the $\mathrm{Co}(\mathbf{1})(\mathrm{hfac})_{2}$ complex were difficult to interpret owing to significant spin-orbit coupling inherent to octahedral high-spin Co" metal ion. As a whole, the reported data clearly demonstrated the favorable coordinating properties of the radical $\mathbf{1}$ which, together with its stability and structural tunability, make it an excellent new building block for establishing more complex metal-radical architectures with interesting magnetic properties.
\end{abstract}

\section{Introduction}

The design and synthesis of new molecular magnetic materials is currently a topic of interest in the materials sciences. ${ }^{[1]}$ One promising avenue is the so-called metal-radical approach that takes advantage of strong intramolecular magnetic exchange interactions which result from the coordination of radical ligands to paramagnetic metal ions. ${ }^{[2]}$ The propagation of these interactions in the solid state through intermolecular exchange coupling can then give rise to cooperative magnetic behavior such as antiferro-, ferri- or ferromagnetism. This approach has enabled the preparation of molecule-based magnetic materials

\footnotetext{
[a] Dr. I. S. Morgan, A. Mansikkamäki, Dr. H. M. Tuononen Department of Chemistry, Nanoscience Center University of Jyväskylä

P.O. Box 35, Fl-40014, University of Jyväskylä, Finland E-mail: ian.s.morgan@jyu.fi, heikki.m.tuononen@jyu.fi

[b] G. A. Zissimou, Dr. P. A. Koutentis

Department of Chemistry

University of Cyprus

P.O. Box 20537, 1678 Nicosia, Cyprus

[c] M. Rouzières, Dr. R. Clérac

CNRS, CRPP

UPR 8641, F-33600, Pessac, France

[d] M. Rouzières, Dr. R. Clérac

Université de Bordeaux, CRPP

UPR 8641, F-33600, Pessac, France
}

ranging from simple one-dimensional coordination polymers to both two- and three-dimensional metal-radical networks. ${ }^{[1]}$

While there exists a number of open shell ligands that are known to coordinate to metal ions, many of them are not indefinitely stable under ambient conditions and cannot therefore be used as building blocks for practical materials. For this reason, a bulk of the reported investigations of metal-radical coordination complexes have employed only a limited number of different ligands such as semiquinones, ${ }^{[3]}$ nitroxides, ${ }^{[4]}$ thiazyls, ${ }^{[5]}$ and verdazyls. ${ }^{[6]}$

Some of the most recent developments in the field of stable radicals chemistry involve 1,2,4-benzotriazinyls, also known as "Blatter radicals". The parent compound was synthesized in $1968,{ }^{[7]}$ but despite its inherent stability, it received only scant attention over the following decades. During

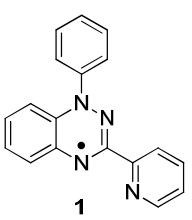
the past five years, we have reported improved syntheses for a growing family of 1,2,4-benzotriazinyls, simultaneously demonstrating that the modifications to the molecular structure do not significantly influence the stability of the radicals. ${ }^{[8]}$ Recently, we published the syntheses of Blatter radicals for coordination purposes, ${ }^{[8 e, 9]}$ and demonstrated that 1-phenyl-3(pyrid-2-yl)-1,4-dihydro-1,2,4-benzotriazin-4-yl (1), which has a bidentate chelation pocket, can act as a coordinating ligand by characterizing its $\mathrm{Cu}(\mathrm{hfac})_{2}$ complex (hfac $=1,1,1,5,5,5-$ hexafluoroacetylacetonato) ${ }^{[9]}$ This complex possessed a strong ferromagnetic metal-radical interaction along with weak antiferromagnetic radical...radical couplings in the solid state.

The bipyridyl-like $N, N^{\prime}$-chelating pocket in the benzotriazinyl 1 suggests that it can have wide coordination chemistry. Thus, the radical is an important new member in the group of stable paramagnetic ligands that can be used to build new molecular magnetic materials. In this context, it was of interest to evaluate the coordination properties of the radical $\mathbf{1}$ in greater detail. Herein we report the synthesis and complete characterization of a series of $3 d$ transition metal complexes of $\mathbf{1}$ with the general formula $\mathrm{M}(\mathbf{1})(\mathrm{hfac})_{2}\left(\mathrm{M}=\mathrm{Mn}^{\|}\right.$2, $\mathrm{Fe}^{\| \prime}$ 3, Coll 4, Nill 5). All complexes were prepared under air with direct $1: 1$ reaction between the radical $\mathbf{1}$ and the corresponding metal-hfac dihydrate, demonstrating both the coordinating ability and the excellent stability of the ligand under ambient conditions. The synthesized metal-radical species 2-5 were characterized primarily by single crystal X-ray crystallography and magnetic susceptibility measurements. Electronic structure calculations were also performed at the density functional and wave function levels of theory to analyze the important magnetic exchange coupling pathways in the solid state and to help the interpretation of the magnetic data. 


\section{Results and Discussion}

Synthesis and characterization. Two routes to the radical 1 have been reported and are briefly outlined below (Scheme 1). ${ }^{[8 e, 9]}$ Route $\mathrm{A}$ begins with the formation of $\mathrm{N}$-phenyl-pyridine-2carbothioamide (6) from picoline, sodium sulfide and aniline, followed by a reaction with phenylhydrazine to afford $N, N^{\prime}$ diphenylpicolinohydrazonamide (7). Ring closure and oxidation is then achieved with $\mathrm{Pd} / \mathrm{C}$ and 1,8-diazabicycloundec-7-ene (DBU) under air. Route B involves the $N^{\prime}$-(2-nitrophenylation) of $N^{\prime}$-phenylpicolinohydrazide (8) via nucleophilic aromatic substitution of 1-fluoro-2-nitrobenzene, to give $N^{\prime}$-(2-nitrophenyl)$N^{\prime}$-phenylpicolinohydrazide (9). Mild reduction of the nitro group followed by an acid-mediated cyclodehydration gives the fused triazine $\mathbf{1 0}$ which is not isolated but treated directly with alkali to give the sought-after radical $\mathbf{1}$. If desired, the benzotriazine $\mathbf{1 0}$ can be isolated and fully characterized before being converted into the radical 1; our best yields (89\%) were obtained using an equivalent amount of $\mathrm{Ag}_{2} \mathrm{O}$ as the oxidant. Crystallographic data of the intermediates $\mathbf{6 , 7}$ and $\mathbf{1 0}$ have been deposited to the Cambridge Crystallographic Data Centre (see the Experimental Section for details).

\section{Route A}

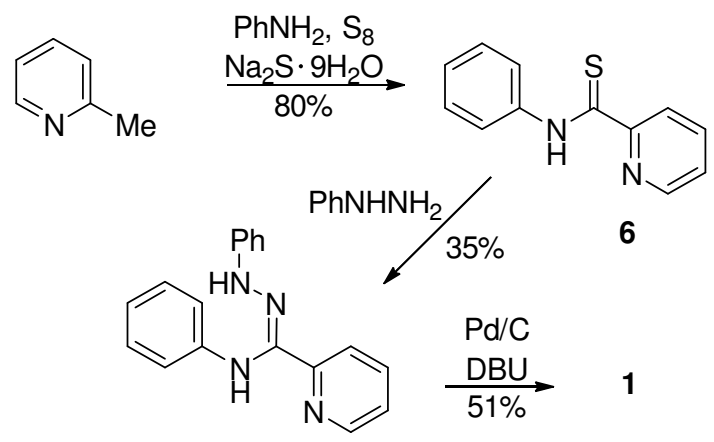

7

\section{Route B}

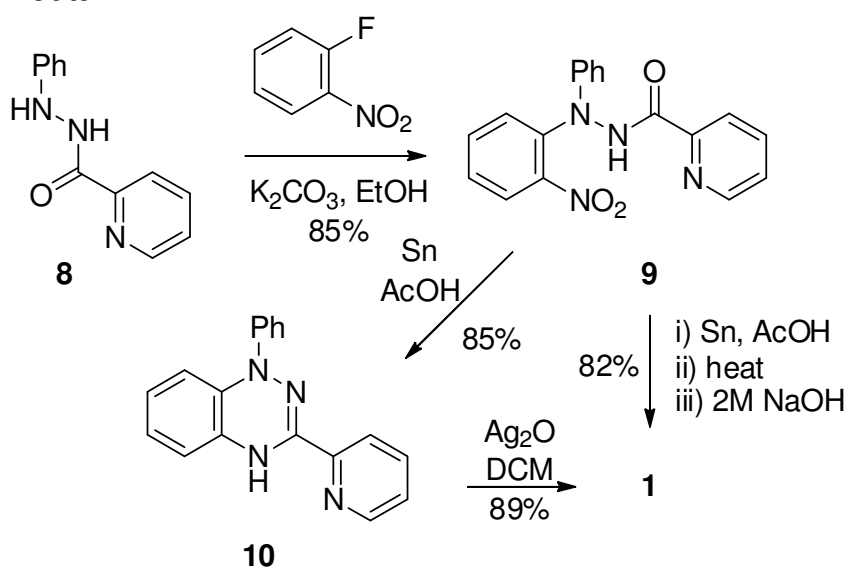

Scheme 1. Two literature syntheses of the coordinating radical 1-phenyl-3(pyrid-2-yl)-1,4-dihydro-1,2,4-benzotriazin-4-yl (1). ${ }^{[8,9]}$
The metal complexes 2-5 were obtained in 30-60\% crystallization yields by reacting chloroform solutions of the radical 1 and the corresponding metal precursors, $\mathrm{M}(\mathrm{hfac})_{2} \cdot 2 \mathrm{H}_{2} \mathrm{O}$, under air.

X-ray crystallography. The X-ray crystal structures of the metal complexes 2-5 revealed that they all consist of pseudooctahedral $\mathrm{M}^{\prime \prime}$ cations with a molecule of the radical 1 coordinated in a bidentate fashion, as expected, along with two anionic auxiliary hfac ligands that fill the coordination sphere of the metal ion. Table 1 lists the crystallographic data for the complexes 2-5 while selected bond lengths are given in Table 2. For complexes 3-5, the data in Table 2 describe only one of the several independent molecules in the asymmetric unit; complete structural data has been deposited to the Cambridge Crystallographic Data Centre (see the Experimental Section for details). The structural data for the complexes 2-5 (Table 2) show that the metrical parameters of the radical ligand are virtually unaffected by its coordination to the metal. The key bond lengths and angles are also very similar to those reported earlier for the uncoordinated ligand. ${ }^{\left[{ }^{[]}\right.}$The metal-nitrogen, and also metal-oxygen, bond lengths decrease by roughly $0.1 \AA$ on progressing from left to right in the $d$-block, which is consistent with the trend in the effective ionic radii for the metal dications. The $\mathrm{Mn}$ " complex 2 showed the greatest distortion from a regular octahedron, which is in agreement with the zero crystal field stabilization energy for a high-spin $d^{5}$ metal ion.

Mn(1)(hfac) 2 (2). Crystals of the $\mathrm{Mn}^{\prime \prime}$ complex 2 belong to the monoclinic space group $P 2_{1} / c$. There is only one complex per asymmetric unit (Figure 1) and four in total in the unit cell. The complexes form infinite columnar stacks along the crystallographic $c$-axis with equal spacing between layers (see ESI). Even though the backbone of the radical ligand remains almost planar, the nearest radical...radical contacts are longer than the sum of vdW radii for the respective elements (3.665(1) and $3.649(7) \AA$ for $\mathrm{N} \cdots \mathrm{N}$ and $\mathrm{C} \cdots \mathrm{C}$ distances, respectively). There are no close intermolecular contacts linking the individual stacks other than $\mathrm{C}-\mathrm{H} \ldots \mathrm{F}$ hydrogen bonds.

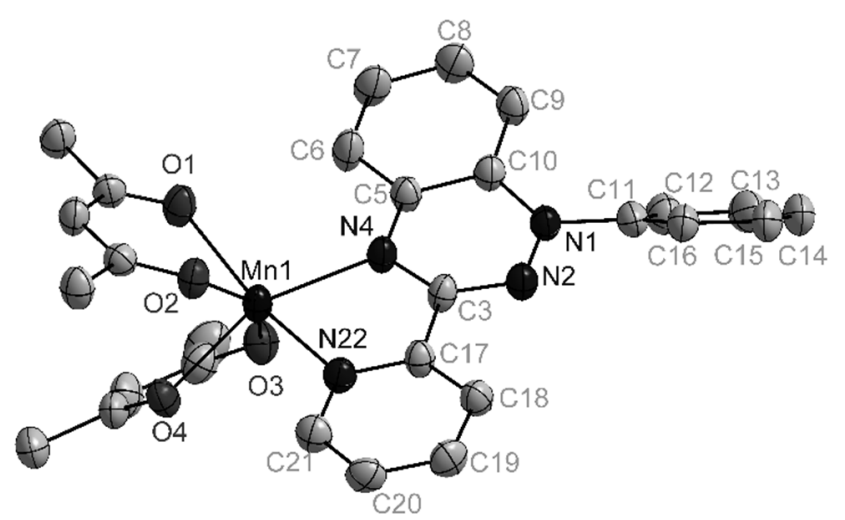

Figure 1. Asymmetric unit in the single crystal X-ray structure of the $\mathrm{Mn}^{\prime \prime}$ complex 2. Thermal ellipsoids are drawn at $50 \%$ probability level and nonessential hydrogen and fluorine atoms are omitted for clarity. 
Table 1. Crystallographic data for the metal complexes $\mathrm{M}(\mathbf{1})(\mathrm{hfac})_{2}\left(\mathrm{M}=\mathrm{Mn}^{\|} \mathbf{2}, \mathrm{Fe}^{\| 1} \mathbf{3}, \mathrm{Co}^{\| \prime} \mathbf{4}, \mathrm{Ni}^{\| \prime} \mathbf{5}\right)$.

\begin{tabular}{|c|c|c|c|c|}
\hline & 2 & 3 & 4 & 5 \\
\hline empirical formula & $\mathrm{C}_{28} \mathrm{H}_{15} \mathrm{~F}_{12} \mathrm{MnN}_{4} \mathrm{O}_{4}$ & $\mathrm{C}_{28} \mathrm{H}_{15} \mathrm{~F}_{12} \mathrm{FeN}_{4} \mathrm{O}_{4}$ & $\mathrm{C}_{28} \mathrm{H}_{15} \mathrm{~F}_{12} \mathrm{CoN}_{4} \mathrm{O}_{4}$ & $\mathrm{C}_{28} \mathrm{H}_{15} \mathrm{~F}_{12} \mathrm{NiN}_{4} \mathrm{O}_{4}$ \\
\hline formula weight & 754.36 & 755.27 & 758.36 & 758.12 \\
\hline crystal system & monoclinic & monoclinic & monoclinic & triclinic \\
\hline space group & $P 21 / c$ & $P 2{ }_{1} / c$ & $P 21 / n$ & $P-1$ \\
\hline crystal size (mm) & $0.30 \times 0.04 \times 0.02$ & $0.40 \times 0.20 \times 0.20$ & $0.40 \times 0.28 \times 0.23$ & $0.01 \times 0.06 \times 0.11$ \\
\hline$T(\mathrm{~K})$ & 123 & 123 & 123 & 123 \\
\hline$Z$ & 4 & 16 & 16 & 4 \\
\hline$a(\AA)$ & $12.9988(4)$ & $29.7657(4)$ & $29.6253(3)$ & $13.1839(5)$ \\
\hline$b(\AA)$ & $28.6304(10)$ & $15.5928(3)$ & $15.63033(10)$ & $14.8176(7)$ \\
\hline$c(\AA)$ & $8.0250(3)$ & $30.1620(6)$ & $30.0733(3)$ & $17.6552(8)$ \\
\hline$\alpha\left(^{\circ}\right)$ & 90 & 90 & 90 & $111.110(4)$ \\
\hline$\beta\left({ }^{\circ}\right)$ & $94.668(3)$ & $119.5000(10)$ & $119.3960(14)$ & $105.077(4)$ \\
\hline$\gamma\left({ }^{\circ}\right)$ & 90 & 90 & 90 & $99.990(4)$ \\
\hline$V\left(\AA^{3}\right)$ & 2976.68 & 12184.2 & 12132.6 & 2967 \\
\hline$\rho_{\text {calc }}\left(\mathrm{g} \mathrm{cm}^{-3}\right)$ & 1.683 & 1.647 & 1.661 & 1.697 \\
\hline GoF & 1.015 & 1.030 & 1.021 & 1.015 \\
\hline$R_{1}$ & 7.60 & 5.59 & 4.38 & 5.52 \\
\hline$w R_{2}$ & 22.7 & 16.8 & 12.1 & 11.3 \\
\hline
\end{tabular}

Table 2. Selected bond lengths $(\AA)$ for the metal complexes 2-5.

\begin{tabular}{lllll}
\hline Bond & $\mathbf{2}(\mathrm{M}=\mathrm{Mn})$ & $\mathbf{3}(\mathrm{M}=\mathrm{Fe})$ & $\mathbf{4}(\mathrm{M}=\mathrm{Co})$ & $\mathbf{5}(\mathrm{M}=\mathrm{Ni})$ \\
\hline $\mathrm{M}-\mathrm{N} 4$ & $2.228(4)$ & $2.140(3)$ & $2.111(2)$ & $2.080(3)$ \\
$\mathrm{M}-\mathrm{N} 22$ & $2.198(4)$ & $2.140(3)$ & $2.087(3)$ & $2.054(3)$ \\
$\mathrm{M}-\mathrm{O} 1$ & $2.144(3)$ & $2.090(3)$ & $2.067(2)$ & $2.043(3)$ \\
$\mathrm{M}-\mathrm{O} 2$ & $2.192(3)$ & $2.096(3)$ & $2.079(2)$ & $2.045(3)$ \\
$\mathrm{M}-\mathrm{O} 3$ & $2.158(3)$ & $2.131(3)$ & $2.050(2)$ & $2.067(3)$ \\
$\mathrm{M}-\mathrm{O} 4$ & $2.185(3)$ & $2.064(3)$ & $2.072(2)$ & $2.038(3)$ \\
$\mathrm{N} 4-\mathrm{C} 5$ & $1.376(6)$ & $1.377(5)$ & $1.392(3)$ & $1.387(5)$ \\
$\mathrm{C} 5-\mathrm{C} 10$ & $1.422(6)$ & $1.413(5)$ & $1.411(4)$ & $1.415(5)$ \\
$\mathrm{C} 10-\mathrm{N} 1$ & $1.388(6)$ & $1.404(5)$ & $1.392(4)$ & $1.390(5)$ \\
$\mathrm{N} 1-\mathrm{N} 2$ & $1.358(6)$ & $1.355(5)$ & $1.363(3)$ & $1.364(5)$ \\
$\mathrm{N} 2-\mathrm{C} 3$ & $1.320(6)$ & $1.313(5)$ & $1.315(3)$ & $1.312(5)$ \\
$\mathrm{C} 3-\mathrm{N} 4$ & $1.343(6)$ & $1.351(5)$ & $1.342(3)$ & $1.349(4)$ \\
$\mathrm{C} 3-\mathrm{C} 17$ & $1.493(6)$ & $1.487(6)$ & $1.485(3)$ & $1.499(6)$ \\
C17-N22 & $1.340(6)$ & $1.346(7)$ & $1.340(3)$ & $1.337(6)$ \\
\hline
\end{tabular}

$\mathrm{Fe}(\mathbf{1})(\mathrm{hfac})_{2}$ (3). Similar to the Mn" complex 2, the crystals of the Fell complex 3 belong to the monoclinic space group $P 2_{1} / c$. However, in this case the asymmetric unit (Figure 2) consists of four metal complexes arranged in two pairs with close intermolecular radical...radical contacts (C...C distances between 3.328(6) and 3.382(7) A). As a result, 16 complexes are present in the unit cell. The complexes form infinite columnar stacks along the crystallographic $b$-axis, but with different packing than that observed for the Mn" complex 2 (see ESI). Owing to the size of the asymmetric unit in the crystal structure of the Fe"l complex 3, the stacks are not identical. There is also greater slippage between individual layers along with some short intermolecular radical $\cdots$ radical contacts between neighboring stacks (C‥C distances of $3.287(7) \AA$ ). While the geometry around the metal center is closer to a regular octahedron than that in the case of $\mathbf{2}$, the geometry of the radical ligand is significantly distorted from planarity for three of the four complexes in the asymmetric unit.

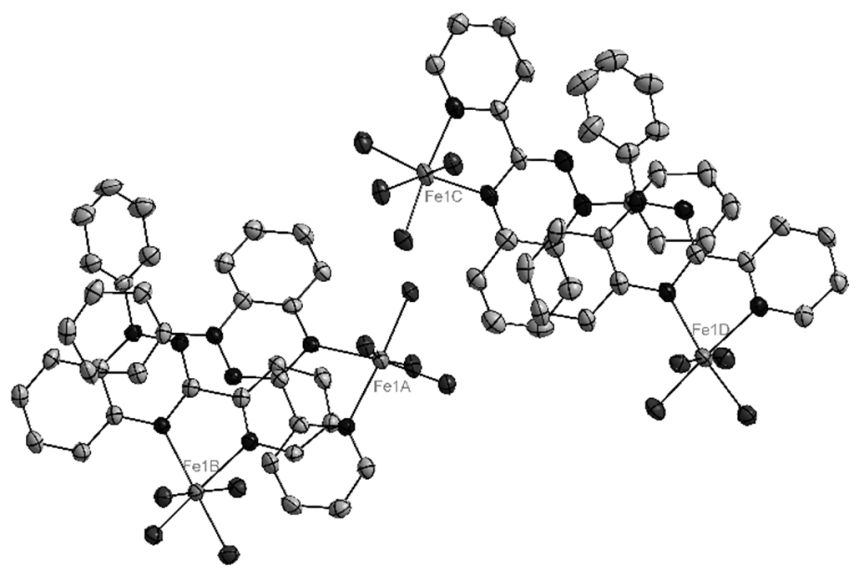

Figure 2. Asymmetric unit in the single crystal X-ray structure of the Fell complex 3. Thermal ellipsoids are drawn at 50\% probability level and nonessential hydrogen, fluorine and carbon atoms are omitted for clarity. 
Co(1)(hfac)2 (4). This system is crystallographically very similar to the $\mathrm{Mn}^{\text {"l }}$ complex 3 . The space group $P 2_{1} / n$ was chosen over $P 2_{1} / c$ as it leads to a smaller $\beta$-angle. The asymmetric unit of the Coll complex 4 (Figure 3) contains four metal complexes arranged in two pairs with close intermolecular radical ...radical contacts within both pairs (C) C distances between $3.343(3)$ and $3.375(4) \AA$ ). Like the $\mathrm{Fe}^{\text {Il }}$ complex 3 , the structure of $\mathbf{4}$ shows that the metal complexes are arranged in columnar stacks along the crystallographic $b$-axis (see ESI) with short intermolecular radical...radical contacts that link the neighboring

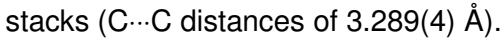

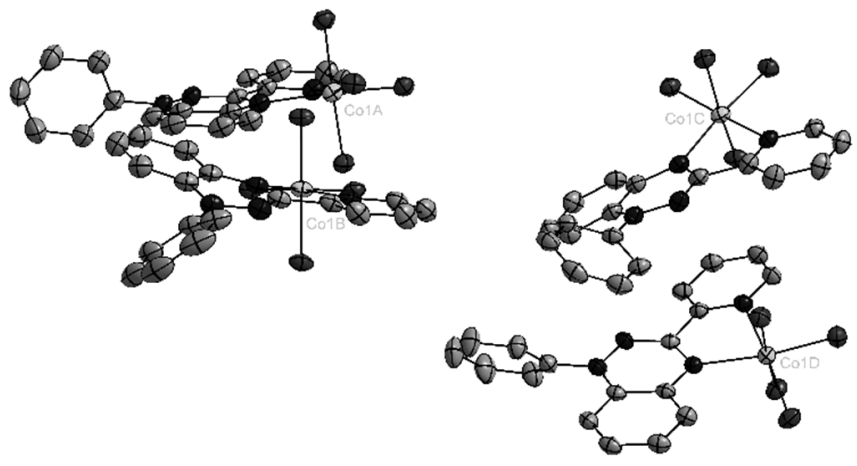

Figure 3. Asymmetric unit in the single crystal X-ray structure of the Co" complex 4. Thermal ellipsoids are drawn at $50 \%$ probability level and nonessential hydrogen, fluorine and carbon atoms are omitted for clarity.

$\mathbf{N i ( 1 ) ( h f a c )})_{2}$ (5). Crystals of the Nill complex 5 are the only ones belonging to a triclinic space group $P-1$. The asymmetric unit consists of a pair of metal complexes with close intermolecular radical $\cdots$ radical contacts (shortest C $\cdots C$ distance $3.310(6) \AA$ ). There are also short $\mathrm{C} \cdots \mathrm{C}$ contacts between the neighboring pairs (shortest C $\cdots C$ distance $3.394(6) \AA$ ) that give rise to infinite slipped stacks along the crystallographic a-axis (see ESI). There appears to be no close intermolecular radical...radical contacts between the stacks.

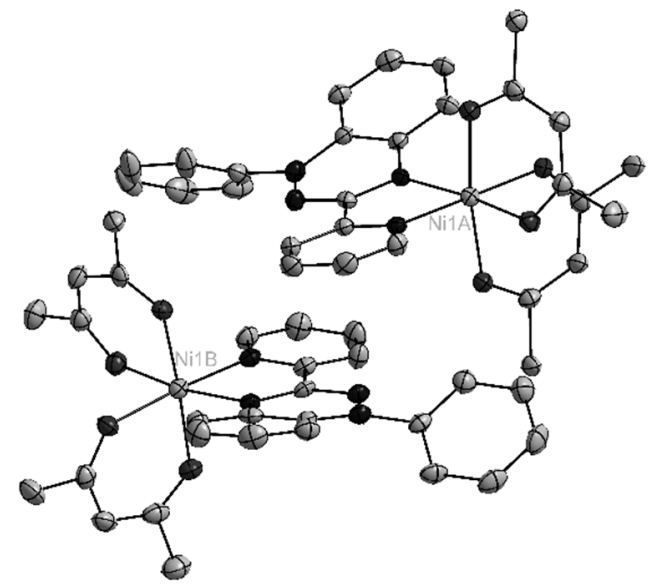

Figure 4. Asymmetric unit in the single crystal X-ray structure of the $\mathrm{Ni}^{\mathrm{il}}$ complex 5. Thermal ellipsoids are drawn at $50 \%$ probability level and nonessential hydrogen and fluorine atoms are omitted for clarity.
Magnetic measurements. The temperature dependence of molar magnetic susceptibility was measured from $300 \mathrm{~K}$ (or 400 $\mathrm{K}$ for $\mathbf{5}$ ) to $1.8 \mathrm{~K}$ for complexes $\mathbf{2}-\mathbf{5}$. The results are displayed below in the form of $\chi T$ vs $T$ plots.

Mn(1)(hfac)2 (2). At room temperature, the $\chi^{T}$ product for the $\mathrm{Mn}$ " complex 2 at $1000 \mathrm{Oe}$ is $3.7 \mathrm{~cm}^{3} \mathrm{~K} \mathrm{~mol}^{-1}$ which is less than that expected for two non-interacting $S_{\mathrm{Mn}}=5 / 2$ and $S_{(1)}=1 / 2$ spin systems (Figure 5). Upon cooling, the $\chi T$ product decreases before levelling off at about $60 \mathrm{~K}$. These features in the $\chi T$ vs $T$ plot indicate the presence of dominant antiferromagnetic interactions between the spins of the $\mathrm{Mn}^{\|}$metal ion and the radical ligand.

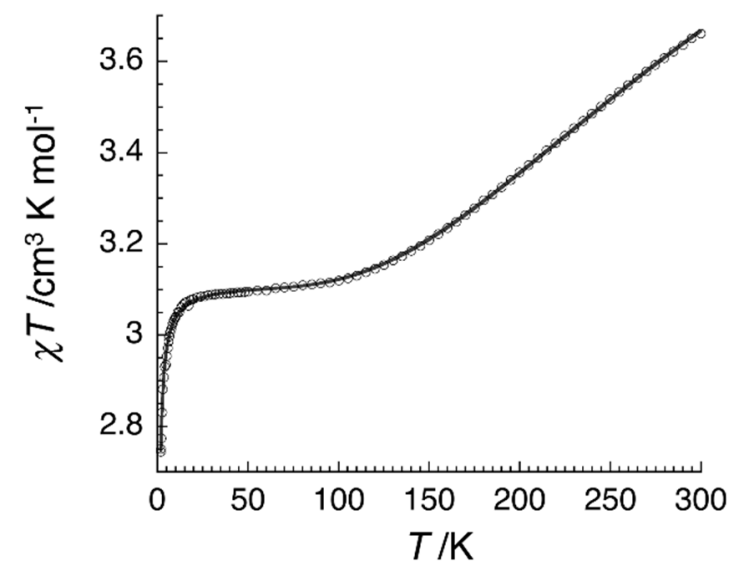

Figure 5. Temperature dependence of the $\chi T$ product for the $\mathrm{Mn}^{\|}$complex 2 at 1000 Oe with $\chi$ defined as the molar magnetic susceptibility equal to $M / H$ per mole of 2 . Measured data (black circles) and best least-squares fit (red line).

Upon further cooling, the $\chi T$ product shows a sharp decrease at $15 \mathrm{~K}$, reaching a value of $2.7 \mathrm{~cm}^{3} \mathrm{~K} \mathrm{~mol}^{-1}$ at $1.8 \mathrm{~K}$. The rapid drop in the $\chi^{T}$ product at low temperatures can be ascribed either to zero-field splitting (ZFS) effects or, more likely as $\mathrm{Mn}^{\prime \prime}$ metal ions and radicals are well-known to possess essentially isotropic spins, to the onset of weak intermolecular antiferromagnetic interactions between complexes of $\mathbf{2}$, even though the single crystal X-ray structure of $\mathbf{2}$ did not show any significant interactions to be present at $123 \mathrm{~K}$. Consequently, the complex 2 can be magnetically viewed as a spin pair composed of $S_{\mathrm{Mn}}=5 / 2$ and $S_{(1)}=1 / 2$ magnetic sites. The magnetic susceptibility of $\mathbf{2}$ can therefore be modelled using an isotropic Heisenberg spin Hamiltonian

$$
\widehat{H}=-2 J_{1}\left(\hat{S}_{\mathrm{Mn}} \cdot \hat{S}_{(\mathbf{1})}\right),
$$

where $J_{1}$ is the metal-radical coupling constant and $\hat{S}_{\mathrm{i}}$ are the appropriate spin operators for the $\mathrm{Mn}$ " metal ion and the radical 1. In the weak-field approximation, the analytical expression of magnetic susceptibility can be determined by applying the van Vleck equation, ${ }^{[10]}$ 


$$
\chi_{0}=\frac{N g_{a v}^{2} \mu_{B}^{2}}{k_{B} T} \frac{10+28 e^{\frac{6 J}{k_{B} T}}}{5+7 e^{\frac{6 J}{k_{B} T}}}
$$

where the parameters have their usual meanings and $g_{\mathrm{av}}$ is the $g$ value of the complex when assuming $g_{\mathrm{Mn}} \approx g_{(1)}$. In order to model the $\chi T$ vs $T$ plot throughout the entire temperature range, intermolecular interactions were introduced to reproduce the experimental low-temperature regime. This was done in the framework of mean-field theory, ${ }^{[1]}$ using the following definition for susceptibility

$$
\chi=\frac{\chi_{0}}{1-\frac{2 z J^{\prime}}{N g_{a v v}^{2} \mu_{B}^{2}} \chi_{0}}
$$

where $\chi_{0}$ is the susceptibility of the non-interacting complexes, $z$ is the number of nearest neighbors and $J$ ' is the magnetic interaction between $\mathrm{Mn}(\mathbf{1})(\mathrm{hfac})_{2}$ complexes. As shown in Figure 5 , this model leads to a good theory-experiment agreement with $J_{1} / k_{\mathrm{B}}=-93(1) \mathrm{K}, z J^{\prime} / k_{\mathrm{B}}=-0.06(1) \mathrm{K}$ and $g_{\mathrm{av}}=2.03(5)$, indicating an $S_{\mathrm{T}}=2$ spin ground state for $\mathrm{Mn}(\mathbf{1})(\mathrm{hfac})_{2}$ (see ESI).

$\mathrm{Fe}(1)(\mathrm{hfac})_{2}$ (3). Magnetic susceptibility measurements for the

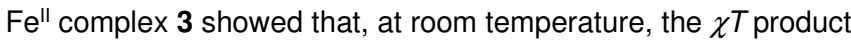
at $1000 \mathrm{Oe}$ is $2.8 \mathrm{~cm}^{3} \mathrm{~K} \mathrm{~mol}^{-1}$ (Figure 6). This is less than that expected for two non-interacting $S_{\mathrm{Fe}}=2$ and $S_{(1)}=1 / 2$ spin systems, suggesting the presence of dominant antiferromagnetic interactions between $\mathrm{Fe}^{\mathrm{ll}}$ and the radical spins.

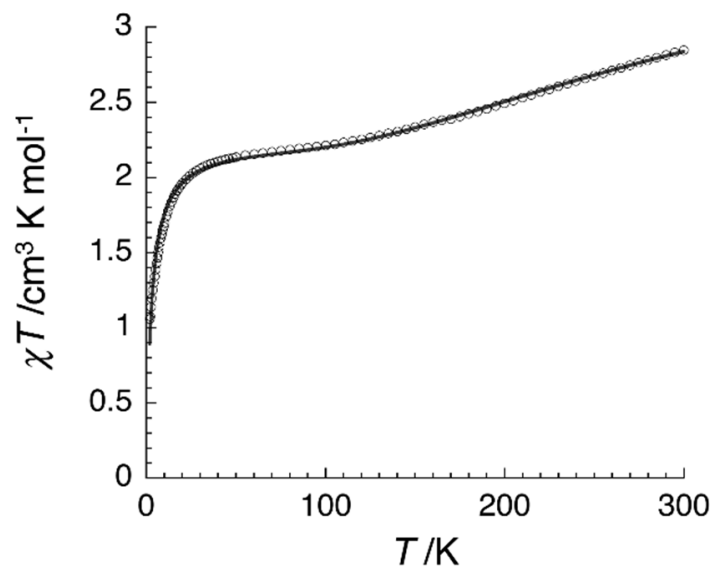

Figure 6. Temperature dependence of the $\chi T$ product for the $\mathrm{Fe}^{\mathrm{Il}}$ complex 3 at 1000 Oe with $\chi$ defined as the molar magnetic susceptibility equal to $M / H$ per mole of 3. Measured data (black circles) and best least-squares fit (red line).

The temperature dependence of the $\chi T$ product shows a similar trend as the $\mathrm{Mn}^{\|}$complex 2 with a gradual decrease between 300 and $30 \mathrm{~K}$. However, in contrast to 2, there is no significant levelling off of the $\chi T$ product at low temperatures, but an abrupt drop in $\chi T$ is observed at $30 \mathrm{~K}$. This behavior can be attributed to the contribution from the intrinsic magnetic anisotropy of $\mathrm{Fe}^{\mathrm{ll}}$ and/or to the onset of weak intermolecular interactions between complexes of $\mathbf{3}$; the possibility for a spin crossover behavior can in this instance be excluded based on experimental and calculated results. ${ }^{[12]}$ The $\chi T$ product reached a minimum value of $1.1 \mathrm{~cm}^{3} \mathrm{~K} \mathrm{~mol}^{-1}$ at $1.8 \mathrm{~K}$.

Crystallography and magnetic measurements suggest that the $\mathrm{Fe}^{\text {Il }}$ complex 3 can be magnetically viewed as a spin pair composed of $S_{\mathrm{Fe}}=2$ and $S_{(1)}=1 / 2$ magnetic sites. The intramolecular exchange interaction can thus be modelled and the $\chi T$ vs $T$ data fitted in the same way as for the $\mathrm{Mn}^{\text {"l }}$ complex 2 by applying the van Vleck equation

$$
\chi_{0}=\frac{N g_{a v}^{2} \mu_{B}^{2}}{4 k_{B} T} \frac{10+35 e^{\frac{5 J}{k_{B} T}}}{2+3 e^{\frac{5 J}{k_{B} T}}},
$$

and treating intermolecular interactions with the mean field theory. ${ }^{[11]}$ A good model of the data for 3 (Figure 6) was achieved using $J_{1} / k_{\mathrm{B}}=-103(5) \mathrm{K}, z J^{\prime} / \mathrm{k}_{\mathrm{B}}=-1.1(3) \mathrm{K}$ and $g_{\mathrm{av}}=$ 2.18(5), leading to an $S_{T}=3 / 2$ spin ground state for $\mathrm{Fe}(\mathbf{1})(\mathrm{hfac})_{2}$ (see ESI).

$\mathrm{Co}(1)(\mathrm{hfac})_{2}$ (4). The room temperature $\chi^{T}$ product of the Coll complex 4 at 1000 Oe is $3.1 \mathrm{~cm}^{3} \mathrm{~K} \mathrm{~mol}^{-1}$ (Figure 7), which is higher than the spin-only value for two non-interacting $S_{C_{0}}=3 / 2$ and $S_{(1)}=1 / 2$ spin systems and indicates that important orbital contributions on the Coll site are likely involved. Upon lowering the temperature, the $\chi^{T}$ product continuously decreases, reaching a minimum value of $0.86 \mathrm{~cm}^{3} \mathrm{~K} \mathrm{~mol}^{-1}$ at $1.8 \mathrm{~K}$. This thermal behavior suggests the existence of an antiferromagnetic interaction between the $\mathrm{Co}^{\text {" }}$ metal ion and the radical ligand that is also superposed to the intrinsic magnetism of the octahedral Co"l site (see ESI). The magnetic properties of the complex $\mathbf{4}$ are difficult to analyze in any further detail because of the magnetic anisotropy associated with Coll metal ions and the fact that the simultaneous treatment of spin-orbit coupling (SOC) effects and exchange interactions leads to Hamiltonians which do not, in general, have straightforward analytical solutions. Thus, it is not possible to extract accurately the metal-radical interaction in complex 4 by fitting the simple $\chi T$ vs $T$ set of data in Figure 7 .

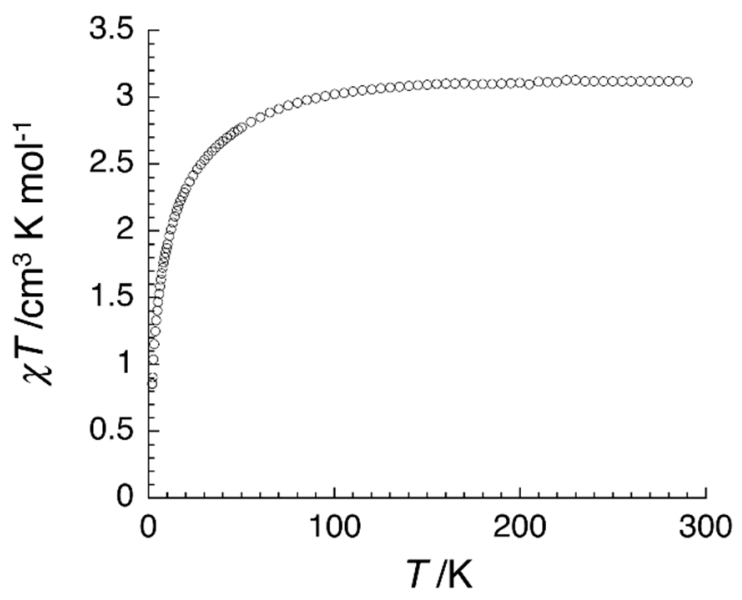

Figure 7. Temperature dependence of the $\chi T$ product for the Co $\mathrm{O}^{\prime \prime}$ complex 4 at 1000 Oe with $\chi$ defined as the molar magnetic susceptibility equal to $M / H$ per mole of 4 . 
$\mathrm{Ni}(\mathbf{1})\left(\right.$ hfac) 2 (5). At $400 \mathrm{~K}$, the $\chi^{T}$ product for the $\mathrm{Nill}^{\mathrm{Il}}$ complex 5 at $1000 \mathrm{Oe}$ is $1.9 \mathrm{~cm}^{3} \mathrm{~K} \mathrm{~mol}^{-1}$ (Figure 8). Upon cooling, the $\chi T$ product first increases up to $2.0 \mathrm{~cm}^{3} \mathrm{~K} \mathrm{~mol}^{-1}$ at $179 \mathrm{~K}$ which is higher than that expected for two non-interacting $S_{\mathrm{Ni}}=1$ and $S_{(1)}$ $=1 / 2$ spin systems and therefore indicates of strong ferromagnetic interactions between the $\mathrm{Ni}^{\mathrm{Il}}$ and the radical spins. Upon further cooling, the $\chi T$ product gradually decreases to 0.14 $\mathrm{cm}^{3} \mathrm{~K} \mathrm{~mol}^{-1}$ at $1.8 \mathrm{~K}$ that can be attributed to the contribution from the intrinsic magnetic anisotropy of $\mathrm{Nill}$ and/or to the onset of weak antiferromagnetic interactions between the radical spins of neighboring complexes of 5 .

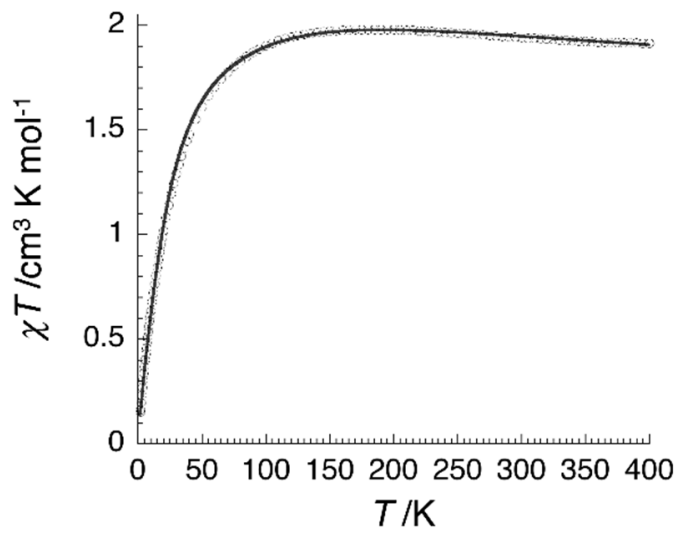

Figure 8. Temperature dependence of the $\chi T$ product for the $\mathrm{Ni}^{\prime \prime}$ complex 5 at 1000 Oe with $\chi$ defined as the molar magnetic susceptibility equal to $M / H$ per mole of 5 . Measured data (black circles) and best simulation (red line).

Solid state structural study showed that there are two different radical $\cdots$ radical contacts between complexes of $\mathbf{5}$. However, only one of these contacts involves carbon atoms that carry spin density. Consequently, a magnetic model based on $\mathrm{Ni}(\mathbf{1})(\mathrm{hfac})_{2}$ pairs stabilized by weak radical $\cdots$ radical interactions was built and the $\chi T$ product for the complex $\mathbf{5}$ fitted to the theoretical susceptibility calculated using the isotropic Heisenberg spin Hamiltonian

$$
\widehat{H}=-2 J_{1}\left(\hat{S}_{N i A} \cdot \hat{S}_{(\mathbf{1}) A}+\hat{S}_{N i B} \cdot \hat{S}_{(\mathbf{1}) B}\right)-2 J_{2}\left(\hat{S}_{(\mathbf{1}) A} \cdot \hat{S}_{(\mathbf{1}) B}\right),
$$

where $J_{1}$ is the metal-radical coupling constant, $J_{2}$ is the radical $\cdots$ radical coupling constant and $\hat{S}_{\mathrm{i}}$ are appropriate spin operators for the two metal centers $(\mathrm{NiA}$ and $\mathrm{NiB})$ and the two radicals ((1)A and (1)B). We note that the magnetic behavior of complex $\mathbf{5}$ is very similar to that reported previously for the analogous $\mathrm{Cu}^{\text {ll }}$ complex, $\mathrm{Cu}(\mathbf{1})(\mathrm{hfac})_{2}{ }^{\left[{ }^{9}\right]}$ Full diagonalization of the above spin Hamiltonian and calculation of the magnetic susceptibility were carried out using the Magpack program. ${ }^{[13]}$ Several sets of values for $J_{1}, J_{2}$ and $g_{\mathrm{av}}$, were found to give equally good simulations of the experimental data with the ranges of possible values being $J_{1} / k_{B}=+80$ to $+160 \mathrm{~K}, J_{2} / k_{B}=$ -55 to $-43 \mathrm{~K}$ and $g_{\mathrm{av}}=2.162$ to 2.075 . Detailed first-principles computational work was therefore conducted to identify which one of the equally acceptable simulations should be considered the most appropriate. ${ }^{[14]}$ Irrespective of the single best simulation, the ranges of possible values for $J_{1}, J_{2}$ and $g_{\text {av }}$ all point towards the same magnetic topology: the interaction between $\mathrm{Nil}^{\prime \prime}$ and radical ligand spins is ferromagnetic $\left(J_{1}\right)$, confirming the $S_{T}=3 / 2$ spin ground state of the $\mathrm{Ni}(\mathbf{1})(\mathrm{hfac})_{2}$ complex $\mathbf{5}$ (see ESI). However, the intermolecular coupling between neighboring complexes of $\mathbf{5}$ is antiferromagnetic $\left(J_{2}\right)$, which ultimately leads to an overall $S_{\mathrm{T}}=0$ spin ground state for a pair of complexes $\mathbf{5}$.

Computational studies. To obtain further insight into the magnetic exchange coupling interactions present in complexes 2-5, density functional theory (DFT) calculations were carried out to determine both the metal-radical $\left(J_{1}\right)$ and the radical...radical $\left(J_{2}\right)$ coupling constants. The magnetic anisotropy of complexes 3-5 was also probed by calculating their ZFS parameters with the effective Hamiltonian approach together with complete active space self-consistent field (CASSCF) and second order $\mathrm{N}$-electron valence state perturbation theory (NEVPT2) wave functions.

The metal-radical coupling constants, $J_{1}$, calculated for the $\mathrm{Mn}^{\mathrm{II}}$ and $\mathrm{Fe}^{\mathrm{Il}}$ complexes 2 and 3 were -102 and $-126 \mathrm{~K}$, respectively. These values are in very good agreement with the experimental results, though in both cases the calculations slightly overestimate the coupling; the tendency of DFT to overemphasize antiferromagnetic interactions owing to the selfinteraction error is well documented in the literature. ${ }^{[15]}$ The strongest radical $\cdots$ radical coupling constants, $J_{2}$, calculated for the complexes 2 and 3 were +0.9 and $-0.4 \mathrm{~K}$, respectively. This suggests a small antiferromagnetic coupling in the $\mathrm{Fe}^{\text {II }}$ complex 3 that is in good agreement with the picture obtained from fitting the experimentally measured $\chi T$ product. The calculated $J_{2}$ value is equally small but negative for the $\mathrm{Mn}$ " complex $\mathbf{2}$, which indicates a ferromagnetic radical...radical interaction that was, however, not observed experimentally. The apparent discrepancy between theory and experiment is ascribed to difficulties in accurate calculation of magnetic coupling constants with DFT methods.

The unquenched angular momentum in the pseudooctahedral Co" metal ion in complex 4 leads to significant anisotropy. This not only makes it difficult to analyze the magnetic behavior of complex 4 experimentally but also computationally. Typically SOC effects in coupling constant calculations can be neglected if the ZFS is considerably smaller than the metal-radical coupling and can, therefore, be treated as a perturbation on the exchange coupling Hamiltonian. If, on the other hand, the ZFS is much larger than the exchange coupling, SOC effects can be introduced first and the metal-radical interaction can then be modelled as an interaction between the radical spin and a pseudo-spin of the lowest Kramers doublet of the Coll ion. In case of the Co" metal complex 4, spin-orbit coupled CASSCF/NEVPT2 calculations revealed that the splitting between the lowest and the first excited Kramers doublet is only $133 \mathrm{~K}$, which means that the ZFS is of the same order of magnitude as the exchange coupling. This leads to strong mixing of SOC and exchange coupling effects in complex 4, which makes it is impossible to reduce the metal-radical coupling to a single effective parameter that could be extracted from the calculated energies. 
The metal-radical coupling $J_{1}$ calculated for the $\mathrm{Nill}$ complex 5 is $+160 \mathrm{~K}$. This result fits well to the higher end of the range of values found to yield acceptable simulations of the experimental $\chi T$ vs $T$ data. The crystal structure of the $\mathrm{Ni}^{l l}$ complex $\mathbf{5}$ showed two distinctively different radical $\cdots$ radical interactions. The radical...radical coupling $J_{2}$ calculated for a single pair of complexes within the asymmetric unit is very small $-2.8 \mathrm{~K}$ as the interaction involves atoms with no spin density. In contrast, the coupling $J_{2}$ calculated for two complexes in nearest neighbor pairs is significantly stronger, $-32.6 \mathrm{~K}$. These results are therefore entirely consistent with the magnetic susceptibility measurements and indicate that from a number of acceptable simulations to the experimental data, the following set of values represents the single best one: $J_{1} / k_{\mathrm{B}}=+145(15) \mathrm{K}, J_{2} / \mathrm{k}_{\mathrm{B}}=$ $-47(3) \mathrm{K}$ and $g_{\mathrm{av}}=2.08(3)$.

The ZFS parameters $D / k_{B}$ and $E / k_{B}$ calculated for the Fell and $\mathrm{Ni}$ " complexes $\mathbf{3}$ and $\mathbf{5}$ are 10.3 and $2.9 \mathrm{~K}$, and -3.1 and 0.3 $\mathrm{K}$, respectively. These indicate the presence of some positive axial anisotropy in the $\mathrm{Fe}^{\mathrm{ll}}$ complex $\mathbf{3}$, the presence of which was also suggested by the magnetic measurements (see ESI). However, the calculated anisotropy parameters are in both cases sufficiently small that their explicit inclusion in the fitting of the $\chi T$ vs $T$ data does not lead to any significant changes in the coupling constants $J_{1}$ and $J_{2}$. This is especially true for the $\mathrm{Nill}$ complex $\mathbf{5}$ for which a range of values was found to give equally acceptable fits, thereby making it very difficult to accurately determine the couplings from magnetic studies. The ZFS parameters calculated for the Coll complex 4 show, rather expectedly, strong positive anisotropy with $D / k_{\mathrm{B}}=+24.4 \mathrm{~K}$ and $E / k_{B}=+3.7 \mathrm{~K}$, which suggests that the ZFS term is a leading term in the spin Hamiltonian and is influencing the magnetic properties of the complex concomitantly to the isotropic coupling

Discussion. In our preliminary work on the coordination chemistry of the radical ligand $1,{ }^{[9]}$ we reported the synthesis, structure and magnetic properties of a Cull complex $\mathrm{Cu}(\mathbf{1})(\mathrm{hfac})_{2}$ Herein we complete the $3 d$ metal series with the analogous $\mathrm{Mn}^{\prime \prime}$, $\mathrm{Fe}^{\prime \prime}, \mathrm{Co}$ " and Ni" complexes 2-5.

Looking at the trend in the metal-radical coupling $J_{1}$, it is observed that the $\mathrm{Mn}^{\mathrm{I}}$ and $\mathrm{Fe}^{\prime \prime}$ ions couple antiferromagnetically with the radical $\mathbf{1}$, whereas $\mathrm{Ni}^{\prime \prime}$ and $\mathrm{Cu}^{\prime \prime}$ couple ferromagnetically; it is difficult to determine the metal-radical interaction in the Coll complex from the experimental and theoretical data. The observed trend in metal-radical coupling can be explained by taking into account the pseudo-octahedral coordination sphere of the divalent metal center and orbital symmetry arguments. The SOMO in benzotriazinyl radicals is a $\pi$-type orbital delocalized throughout the molecular backbone (see ESI). ${ }^{[9]}$ In case of $\mathrm{Mn}^{\text {"l }}$ and Fe" complexes, there is a nonzero (non-orthogonal) orbital overlap between the SOMO of 1 and the metal $t_{2 g}$ orbitals, resulting in a dominant antiferromagnetic interaction between spin carriers. In contrast, the unpaired electrons in the $\mathrm{Ni}^{\mathrm{Il}}$ and $\mathrm{Cu}^{\mathrm{ll}}$ complexes are located on the $e_{g}$ orbitals which have zero (orthogonal) overlap with the SOMO of $\mathbf{1}$, thereby giving rise to ferromagnetic coupling of the spins.
Since the radical $\mathbf{1}$ is the first coordinating benzotriazinyl radical, the metal-radical couplings in 2-5 need to be compared to metal complexes of other neutral radicals reported in the literature. In this respect, coordination compounds of verdazyl radicals serve as an appropriate reference point because of the bipyridyl-like $N, N^{\prime}$-chelating pocket of the radical along with other structural similarities to benzotriazinyls. ${ }^{[6]}$

The antiferromagnetic coupling between the $\mathrm{Mn}$ " metal ion and the benzotriazinyl radical in complex $2(-93 \mathrm{~K})$ is stronger than that observed for an analogous verdazyl complex employing the 1,5-dimethyl-3-(pyrid-2-yl)-6-oxoverdazyl (pyVDZ) ligand $(-32 \mathrm{~K}) \cdot{ }^{[16]}$ The significantly stronger coupling in 2 is somewhat surprising as both radical ligands have similar SOMOs that are nodal at the pyridyl nitrogen atoms. A more detailed comparison of the metal complexes is unfortunately impossible as no structural data of Mn(pyVDZ)(hfac) $)_{2}$ has been reported in the literature. However, crystallographic and magnetic analyses have been published for a related bimetallic complex (hfac) $)_{2} \mathrm{Mn}(\mathrm{pmVDZ}) \mathrm{Mn}(\mathrm{hfac})_{2}$ with the bridging 1,5dimethyl-3-(4,6-dimethylpyrimid-2-yl)-6-oxoverdazyl (pmVDZ) ligand. ${ }^{[17]}$ For this system, the metal-radical coupling is very similar to that in $\mathrm{Mn}$ (pyVDZ)(hfac) $2(-35 \mathrm{~K})$ and the key $\mathrm{Mn}-\mathrm{N}$ bond length is $2.326(4) \AA$ which is significantly longer than that in complex 2, 2.198(4) $\AA$.

There are no reports on verdazyl complexes analogous to the $\mathrm{Fe}^{\text {II }}$ and $\mathrm{Co}$ " systems, $\mathbf{3}$ and $\mathbf{4}$. Interestingly, there are only a few reports of neutral radical coordination complexes involving the $\mathrm{Fe}^{\text {ll }}$ metal ion. For example, $\mathrm{Fe}(\mathrm{hfac})_{2}$ does not form a stable coordination complex with (2,2,6,6-tetramethylpiperidin-1-yl)oxyl (TEMPO) ${ }^{[18]}$ but does so when it is reacted with the 4-(pyrid-2yl)-1,2,3,5-dithiadiazolyl (pyDTDA) radical ligand..19] However, when sublimed, the complex $\mathrm{Fe}($ pyDTDA)(hfac) 2 thermally decomposes into a coordination complex that contains a diamagnetic ligand. The coupling between the benzotriazinyl radical and the $\mathrm{Fe}^{\mathrm{Il}}$ metal ion in complex 3 was found to be antiferromagnetic $(-103 \mathrm{~K})$ and significantly stronger than that reported for the related $\mathrm{Fe}\left(\right.$ pyDTDA) $(\mathrm{hfac})_{2}$ complex $(-60 \mathrm{~K}) .^{[19]}$ A structural comparison of $\mathbf{3}$ and $\mathrm{Fe}(\mathrm{pyDTDA})(\mathrm{hfac})_{2}$ shows that the key metal-nitrogen bond distances are not statistically different between the two: 2.140(3) and 2.158(14) $\AA$ for 3 and $\mathrm{Fe}($ pyDTDA)(hfac) 2 , respectively. However, according to population analyses of spin densities, the coordinating nitrogen atom in the radical $\mathbf{1}$ carries more spin density than that in the pyDTDA ligand, which offers a plausible explanation for the observed coupling strengths.

The ferromagnetic coupling between the $\mathrm{Nil}$ metal ion and the radical $\mathbf{1}$ in complex $\mathbf{5}(+160 \mathrm{~K})$ is very similar to that reported for the verdazyl complexes $\mathrm{Ni}(\text { pyVDZ)(hfac) })_{2}(+173 \mathrm{~K})$ and (hfac) ${ }_{2} \mathrm{Ni}(\mathrm{pmVDZ}) \mathrm{Ni}(\mathrm{hfac})_{2}$ (+158 K). ${ }^{[16,17]} \quad$ Unfortunately there are no published structural reports of the two $\mathrm{Ni}^{\prime \prime}$ verdazyl compounds, which precludes further comparison to the complex 5. However, population analyses of spin densities indicate that the coordinating nitrogen atoms in pyVDZ and pmVDZ radicals carry more spin density than that in the ligand $\mathbf{1}$. The nearly identical couplings can then be rationalized by assuming that the key metal-nitrogen bond lengths are much longer in the two 
verdazyl complexes, similarly to what was observed for the analogous $\mathrm{Mn}^{\mathrm{Il}}$ complexes of pyVDZ, pmVDZ and $\mathbf{1}$.

The radical...radical couplings $J_{2}$ in complexes 2-5 were found to be very small even though the crystal structures revealed close (shorter than the sum of $\mathrm{vdW}$ radii) intermolecular $\mathrm{C} \cdots \mathrm{C}$ contacts between neighboring radicals. This can be explained by comparing the morphology of the SOMO of 1 (see ESI) with the observed interactions, which shows that the majority of the close $\mathrm{C} \cdots \mathrm{C}$ contacts observed in the solid state involve carbon atoms that carry no spin density. This readily explains the weakness of the $J_{2}$ coupling in complexes $\mathbf{2}$ and $\mathbf{3}$. In contrast, the $\mathrm{Ni}^{\prime \prime}$ complex $\mathbf{5}$, along with the previously reported $\mathrm{Cu}^{11}$ system, ${ }^{\left[{ }^{[9]}\right.}$ display an order of magnitude stronger antiferromagnetic radical $\cdots$ radical coupling due to the greater overlap of radical SOMOs that is in these cases allowed by more favorable crystallographic packing. However, in all of the reported complexes $\mathbf{2 - 5}$, the sterically bulky hfac auxiliary ligands prevent more efficient stacking of the coordinated benzotriazinyls which could lead to stronger radical-..radical interactions and even ferromagnetic coupling of the spins. Even though the benzotriazinyl radical $\mathbf{1}$ forms strongly antiferromagnetically coupled pairs in the solid state $(J=-412$ $\mathrm{K}),{ }^{[9]}$ the potential to functionalize Blatter radicals has led to a number of derivatives of which several demonstrate ferromagnetic coupling of spins due to the formation of perfectly slipped $\pi$-stacks. ${ }^{[20]}$ It is therefore very likely that with appropriate modifications to both the molecular structure of the coordinating benzotriazinyl radical ligand and the steric bulk of the auxiliary ligands, benzotriazinyl complexes in which both the metalradical and the radical $\cdots$ radical interactions are ferromagnetic in nature could be realized. This would require careful fine-tuning of the steric and electronic properties of the building blocks to achieve the correct degree of stack slippage. ${ }^{[21]}$ Fortunately, the inherent stability of both the benzotriazinyl radical and its metal complexes expedites this process.

\section{Conclusion}

In this contribution, we have prepared the first series of benzotriazinyl complexes with divalent paramagnetic $3 d$ metal cations using the hexafluoroacetalacetonate as the auxiliary ligand of choice. The synthesized complexes demonstrate that the employed neutral radical ligand 1-phenyl-3-(pyrid-2-yl)-1,4dihydro-1,2,4-benzotriazin-4-yl engages in strong intramolecular exchange interactions with the metal ions $\mathrm{Mn}^{\prime \prime}, \mathrm{Fe}^{\prime \prime}, \mathrm{Co}^{\prime \prime}$ and $\mathrm{Ni}$ ", and the resulting pseudo-octahedral coordination complexes remain air and water stable. Magnetic susceptibility measurements, supported by crystallographic and computational investigations, revealed that the metal-radical coupling is antiferromagnetic in the $\mathrm{Mn}^{\|}$and $\mathrm{Fe}^{\mathrm{ll}}$ complexes, whereas in the $\mathrm{Ni}^{\prime l}$ system, the unpaired electrons on the metal ion couple ferromagnetically with the ligand spin. On the other hand, the magnetic properties of the analogous Coll complex are difficult to interpret due to the intrinsic magnetic anisotropy of high-spin Co" metal ion in an octahedral ligand field. The ferromagnetic coupling in the synthesized $\mathrm{Ni}^{\prime \prime}$ complex is similar in strength to that in related verdazyl compounds, which highlights the potential in coordinating benzotriazinyl radicals for the synthesis of strongly magnetically coupled metal-radical architectures. The unique binding abilities of the employed benzotriazinyl radical ligand are also underlined by the stability of the synthesized Fe"l complex which is only the second structurally characterized example of its kind. As a whole, the results reported herein are an important addition to the chemistry of benzotriazinyl radicals and form an important benchmark for the synthesis of new metal-benzotriazinyl complexes with different metal centers, modified radical structures and alternative auxiliary ligands. The benzotriazinyl structure is highly modifiable and can be easily manipulated to produce bisbidentate coordination pockets for creating homo- or heterobimetallic metal-radical complexes potentially displaying three-dimensional magnetic ordering in the solid state. Efforts to this end are in progress in our groups.

\section{Experimental Section}

\section{Synthetic details}

All reactions were performed under ambient conditions unless otherwise stated. A standard literature procedure was used for the preparation of bis(hexafluoroacetylacetonato)metal(II) dihydrates, $\mathrm{M}(\mathrm{hfac})_{2} \cdot 2 \mathrm{H}_{2} \mathrm{O}(\mathrm{M}=$ $\mathrm{Mn}, \mathrm{Fe}, \mathrm{Co}, \mathrm{Ni}){ }^{\left[{ }^{22]}\right.}$ All other reagents were purchased from commercial sources and used as received. The solvents used were of at least reagent grade.

1-Phenyl-3-(pyrid-2-yl)-1,4-dihydro-1,2,4-benzotriazin-4-yl (1) was prepared according to two literature procedures. ${ }^{[8,9]}$ Spectroscopic data for the synthetic intermediates $\mathrm{N}$-phenyl-pyridine-2-carbothioamide (6) and $N, N^{\prime}$-diphenylpicolinohydrazonamide (7) have previously been reported, ${ }^{[23]}$ for which reason only the crystal structures of these compounds are described herein. The intermediate 1-phenyl-3-(pyrid-2yl)-1,4-dihydro-1,2,4-benzotriazine (10) has previously been used as an in situ reagent for the synthesis of $1 .^{[8]}$ Herein the full synthetic details for 10 are provided along with its complete characterization and conversion to the radical 1.

1-Phenyl-3-(pyrid-2-yl)-1,4-dihydrobenzo[e][1,2,4]triazine (10). To a vigorously stirred suspension of $N^{\prime}$-(2-nitrophenyl)- $N$ '-phenyl-2-pyridinecarbohydrazide (9) $(334 \mathrm{mg}, 1.0 \mathrm{mmol})$ in glacial acetic acid $(5 \mathrm{~mL})$, tin powder $(475 \mathrm{mg}, 4.0 \mathrm{mmol}$ ) was added in one portion. The reaction mixture was stirred at ca. $20^{\circ} \mathrm{C}$ for $30 \mathrm{~min}$, after which it was immersed in a preheated Wood's metal bath, ca. $140{ }^{\circ} \mathrm{C}$. After heating at reflux for $10 \mathrm{~min}$, the mixture was allowed to cool to ca. $20{ }^{\circ} \mathrm{C}$, diluted with $\mathrm{DCM}$ $(50 \mathrm{~mL})$, filtered, washed with $2 \mathrm{M} \mathrm{NaOH}(2 \times 50 \mathrm{~mL})$ and water $(50 \mathrm{~mL})$. The organic phase was separated, dried $\left(\mathrm{Na}_{2} \mathrm{SO}_{4}\right)$ and the volatiles were removed in vacuo. The residue was dissolved in DCM $(2 \mathrm{~mL})$ and chromatographed on silica ( $t$-BuOMe) to give 10 as orange needles (243 $\mathrm{mg}, 85 \%$ ). Melting point (DSC): onset $126.9{ }^{\circ} \mathrm{C}$, peak max $127.5^{\circ} \mathrm{C}$ (from EtOH); ${ }^{1} \mathrm{H}$ NMR (500 MHz, DMSO- $\left.d_{6}\right): 8.86(1 \mathrm{H}, \mathrm{s}, \mathrm{NH}), 8.66(1 \mathrm{H}, \mathrm{d}, J$ 4.7, $\operatorname{Ar} H), 8.06(1 \mathrm{H}, \mathrm{d}, J 7.9, \operatorname{Ar} H), 7.91(1 \mathrm{H}$, ddd, J 15.5, 7.8, 1.5, Ar H), $7.53(1 \mathrm{H}$, ddd, J 12.2, 5.8, 0.7, Ar H), $7.47(2 \mathrm{H}, \mathrm{d}, J 7.6, \operatorname{Ar} H), 7.42(2 \mathrm{H}$, dd, J 7.8, 7.8, Ar H), $7.13(1 \mathrm{H}, \mathrm{dd}, J$ 7.2, 7.2, Ar H), $6.96(1 \mathrm{H}, \mathrm{dd}, J 7.6$, 1.1, $\operatorname{Ar} H), 6.75(1 \mathrm{H}, \mathrm{ddd}, J 15.1,7.6,1.0, \operatorname{Ar} H), 6.68(1 \mathrm{H}, \mathrm{ddd}, J 15.4$, 7.7, 1.2, Ar H), $6.42(1 \mathrm{H}, \mathrm{d}, J 7.7, \mathrm{Ar} H)$; ${ }^{13} \mathrm{C}$ NMR $(125 \mathrm{MHz}$, DMSO-d 6 ): 148.2 (d), 147.8 (s), 146.4 (s), 143.5 (s), 137.0 (d), 133.5 (s), 133.1 (s), 129.0 (d), 124.9 (d), 123.5 (d), 123.4 (d), 123.0 (d), 121.2 (d), 120.5 (d), 114.4 (d), 111.4 (d); IR: $\tilde{v}_{\max } 3368$ (w), 3061 (w), 3011 (w), 1647 (w), 
$1587(\mathrm{~m}), 1564(\mathrm{w}), 1520(\mathrm{w}), 1499(\mathrm{~m}), 1491(\mathrm{~m}), 1481(\mathrm{~m}), 1470(\mathrm{~m})$ $1447(\mathrm{~m}), 1420(\mathrm{~m}), 1352(\mathrm{w}), 1323(\mathrm{w}), 1306(\mathrm{w}), 1296(\mathrm{~m}), 1267(\mathrm{~m})$, $1248(w), 1236(w), 1182(m), 1171(w), 1155(w), 1146(w), 1117(w)$, $1097(w), 1076(w), 1047(w), 1028(w), 1016(w), 995(w), 959(w), 918$ (w), $899(w), 891(w), 878(w), 854(w), 849(w), 839(w), 831(w), 787$ (m), 766 (w), 750 (s), 737 (s); UV/Vis: $\lambda_{\max }(\mathrm{DCM}) / \mathrm{nm} 269$ (log $\varepsilon$ 3.28), $309 \inf (2.97), 426$ (2.40); $R_{f}(t$-BuOMe:n-hexane) 0.57; MALDI-TOF $(\mathrm{m} / \mathrm{z}): 287\left(\mathrm{MH}^{+}, 10 \%\right), 286\left(\mathrm{M}^{+}, 100\right), 285$ (1); elemental analysis calcd (\%) for $\mathrm{C}_{18} \mathrm{H}_{14} \mathrm{~N}_{4}$ : C, $75.50 ; \mathrm{H}, 4.93 ; \mathrm{N}, 19.57$; found: C, 75.35; H, 4.83; N, 19.48

Conversion of 10 to 1. To a solution of 1-phenyl-3-(pyrid-2-yl)-1,4dihydrobenzo[e][1,2,4]triazine (10) $(286 \mathrm{mg}, 1.0 \mathrm{mmol})$ in DCM $(10 \mathrm{~mL})$ was added $\mathrm{Ag}_{2} \mathrm{O}$ (232 $\mathrm{mg}, 1.0 \mathrm{mmol}$ ) in one portion. The suspension was vigorously stirred at $\mathrm{ca} .20{ }^{\circ} \mathrm{C}$ for $30 \mathrm{~h}$, upon which time the mixture was filtered (Celite $\AA)$, washed with additional DCM and chromatographed (basic alumina, DCM/t-BuOMe) to afford 1 as black needles $(254 \mathrm{mg}$, $89 \%$ ). Melting point (DSC): onset $179.7{ }^{\circ} \mathrm{C}$, peak max $181.7{ }^{\circ} \mathrm{C}$, decomposition onset $185.3{ }^{\circ} \mathrm{C}$, peak max $186.2{ }^{\circ} \mathrm{C}$ (from $\mathrm{PhH}$ ); UV/Vis: $\lambda_{\max }(\mathrm{DCM}) / \mathrm{nm} 257 \mathrm{inf}(\log \varepsilon 3.31), 276$ (3.39), 320 (2.79), 363 (2.74), 424 (2.43), 493 (2.08); $R_{\mathfrak{f}}\left(\mathrm{Al}_{2} \mathrm{O}_{3}: \mathrm{DCM}\right)$ 0.40; MALDI-TOF $(\mathrm{m} / \mathrm{z}): 287$ $\left(\mathrm{MH}^{+}+1,7 \%\right), 286\left(\mathrm{MH}^{+}, 35\right), 285\left(\mathrm{M}^{+}, 100\right), 267$ (1), 185 (1), identical to an authentic sample of $\mathbf{1}$.

$\mathbf{M}(\mathbf{1})(\mathrm{hfac})_{2}(\mathbf{2}-5)$. A $10 \mathrm{~mL}$ chloroform solution of $\mathrm{M}(\mathrm{hfac})_{2} \cdot 2 \mathrm{H}_{2} \mathrm{O}(\mathrm{M}=$ $\mathrm{Mn}, \mathrm{Fe}, \mathrm{Co}, \mathrm{Ni}$ ) was slowly added to a $10 \mathrm{~mL}$ equimolar solution of the benzotriazinyl 1 in chloroform and stirred at room temperature for $1 \mathrm{~h}$. The solvent was evaporated under reduced pressure and the corresponding complexes were quantitatively recovered as purple powders. Recrystallization by slow diffusion of pentanes into a chloroform solution yielded large crystals of complexes 2-5 suitable for both crystallography and magnetic susceptibility measurements.

Characterization data for $\mathrm{Fe}(1)(\mathrm{hfac})_{2}$ (2). Purple prisms recrystallized from chloroform:pentane (51 mg, 42\%). IR: $\tilde{v}_{\max } 1630(\mathrm{~s}), 1604(\mathrm{w}), 1588$ (w), $1570(\mathrm{~m}), 1549(\mathrm{~m}), 1523(\mathrm{~m}), 1505(\mathrm{~m}), 1475(\mathrm{~s}), 1418(\mathrm{~m}), 1361$ (w), $1346(\mathrm{w}), 1286(\mathrm{~s}), 1250(\mathrm{~s}), 1194(\mathrm{~s}), 1138(\mathrm{~s}), 1098(\mathrm{w}), 1074(\mathrm{w})$, $1050(w), 1019(m), 1000(m), 949(m), 919(w), 855(w), 809(w), 793$ $(\mathrm{m}), 772(\mathrm{~m}), 757(\mathrm{~m}), 747(\mathrm{~m}), 696(\mathrm{~m}), 677(\mathrm{~m}), 663(\mathrm{~m}), 645(\mathrm{~s}), 623$ $(\mathrm{m}), 584(\mathrm{~m}), 528(\mathrm{w}), 510 \mathrm{~cm}^{-1}(\mathrm{w})$; elemental analysis calcd $(\%)$ for $\mathrm{C}_{28} \mathrm{H}_{15} \mathrm{~F}_{12} \mathrm{~N}_{4} \mathrm{O}_{4} \mathrm{Fe}$ : C, $44.53, \mathrm{H}, 2.00, \mathrm{~N}, 7.42$; found: $\mathrm{C}, 44.76, \mathrm{H}, 2.30, \mathrm{~N}$ 7.54 .

Characterization data for $\mathrm{Mn}(\mathbf{1})(\mathrm{hfac})_{2}$ (3). Purple prisms recrystallized from chloroform:pentane (50 mg, 46\%). IR: $\tilde{v}_{\max } 1647$ (s), 1640, 1651 (s), 1603, $1589(\mathrm{w}), 1570(\mathrm{~m}), 1555(\mathrm{~m}), 1528(\mathrm{~m}), 1493(\mathrm{w}), 1483(\mathrm{~m}), 1454$ $(w), 1419(w), 1395(w), 1356(w), 1345(w), 1302(w), 1252(s), 1195(s)$, 1135 (s), $1097(\mathrm{~s}), 1049(\mathrm{~m}), 1018(\mathrm{~m}), 1001(\mathrm{w}), 949(\mathrm{w}), 922(\mathrm{w}), 910$ (w), $888(w), 856(w), 822(w), 795(m), 769(m), 761(m), 746(m), 740$ $(\mathrm{m}), 696(\mathrm{~m}), 676(\mathrm{~m}), 661(\mathrm{~m}), 643(\mathrm{~m}), 622(\mathrm{w}), 582(\mathrm{~m}), 527(\mathrm{w}), 511$ $\mathrm{cm}^{-1}(\mathrm{w})$; elemental analysis calcd (\%) for $\mathrm{C}_{28} \mathrm{H}_{15} \mathrm{~F}_{12} \mathrm{~N}_{4} \mathrm{O}_{4} \mathrm{Mn}: \mathrm{C}, 44.58, \mathrm{H}$, 2.00, N, 7.43; found: C, 44.70, H, 2.13, N, 7.22.

Characterization data for $\mathrm{Co}(1)(\mathrm{hfac})_{2}(4)$. Purple prisms recrystallized from chloroform:pentane (33 mg, 30\%). IR: $\tilde{v}_{\max } 1634$ (s), 1606 (w), 1588 (w), $1570(\mathrm{~m}), 1553(\mathrm{~m}), 1526(\mathrm{~m}), 1505(\mathrm{~m}), 1484(\mathrm{~s}), 1455(\mathrm{~m}), 1491$ (s), $1362(\mathrm{~m}), 1347(\mathrm{w}), 1287(\mathrm{~s}), 1250(\mathrm{~s}), 1195(\mathrm{~s}), 1162(\mathrm{w}), 1141(\mathrm{~s})$, $1096(w), 1051(w), 1022(w), 1000(w), 948(w), 919(w), 919(w), 906$ $(w), 884(w), 855(w), 810(w), 793(m), 773(m), 756(m), 748(m), 696$ $(\mathrm{m}), 677(\mathrm{w}), 666(\mathrm{~m}), 646(\mathrm{~s}), 605(\mathrm{w}), 583(\mathrm{w}), 527(\mathrm{w}), 510 \mathrm{~cm}^{-1}(\mathrm{w})$; elemental analysis calcd (\%) for $\mathrm{C}_{28} \mathrm{H}_{15} \mathrm{~F}_{12} \mathrm{~N}_{4} \mathrm{O}_{4} \mathrm{Co}: \mathrm{C}, 44.35, \mathrm{H}, 1.99, \mathrm{~N}$, 7.39; found: C, 44.01, H, 1.98, N, 7.31.

Caracterization data for $\mathrm{Ni}(\mathbf{1})(\mathrm{hfac})_{2}(5)$. Purple prisms recrystallized from chloroform:pentane (71 mg, 64\%). IR: $\tilde{v}_{\max } 1651(\mathrm{~s}), 1641(\mathrm{~s}), 1609$ $(\mathrm{w}), 1590(\mathrm{w}), 1572(\mathrm{~m}), 1552(\mathrm{~m}), 1524(\mathrm{~m}), 1481(\mathrm{~s}), 1456(\mathrm{w}), 1420$ $(w), 1363(w), 1343(w), 1313(w), 1288(w), 1252(s), 1194(s), 1139(s)$, $1049(m), 1051(w), 1025(w), 997(w), 949(w), 920(w), 858(w), 808(w)$, $793(\mathrm{~m}), 769(\mathrm{~m}), 760(\mathrm{~m}), 747(\mathrm{~m}), 696(\mathrm{~m}), 678(\mathrm{~s}), 649(\mathrm{w}), 625(\mathrm{w})$, $606(\mathrm{w}), 584(\mathrm{~m}), 529(\mathrm{w}), 510 \mathrm{~cm}^{-1}(\mathrm{w})$; elemental analysis calcd (\%) for $\mathrm{C}_{28} \mathrm{H}_{15} \mathrm{~F}_{12} \mathrm{~N}_{4} \mathrm{O}_{4} \mathrm{Ni}$ : C, 44.36, H, 1.99, N, 7.39; found: C, 44.56, H, 2.21, N, 7.51 .

\section{Instrumental analyses}

Elemental analyses were performed using Elementar Vario EL III analyzer (CHNOS). Infrared spectra of the complexes 2-5 were recorded on a Bruker Alpha Platinum-ATR FTIR spectrometer at $2 \mathrm{~cm}^{-1}$ resolution. The magnetization and magnetic susceptibility measurements were carried out with the use of MPMS-XL Quantum Design SQUID magnetometer. This instrument works between 1.8 and $400 \mathrm{~K}$ with applied DC fields ranging from -7 to $7 \mathrm{~T}$. Measurements were performed on polycrystalline samples of $\mathbf{2}-\mathbf{5}(15.20, \mathbf{1 3 . 5 3}, 17.05$ and $34.42 \mathrm{mg}$ respectively) sealed in a polyethylene bag $(3 \times 0.5 \times 0.02 \mathrm{~cm})$. Prior to the experiments, the field-dependent magnetization was measured at $100 \mathrm{~K}$ in order to confirm the absence of any bulk ferromagnetic impurities. Alternating current susceptibility measurements were also performed with an oscillating field of 3 Oe with frequencies from 1 to $1500 \mathrm{~Hz}$. No out-of-phase was detected above $1.8 \mathrm{~K}$. The magnetic data were corrected for the sample holder, paratone oil and the intrinsic diamagnetic contributions. All single crystal X-ray data were collected with Agilent SuperNova diffractometer equipped with multilayer optics monochromated dual source (Cu and Mo) Atlas detector, using $\mathrm{Cu}_{\mathrm{K}_{\alpha}}(\lambda=$ $1.54184 \AA$ A) radiation at $123 \mathrm{~K}$. Data acquisitions, reductions and analytical face-index based absorption corrections were made using CrysAlis ${ }^{\mathrm{PRO}}$ program. ${ }^{[24]}$ The structures were solved with either ShelXS ${ }^{[25]}$ or Superflip ${ }^{[26]}$ programs and refined on $F^{2}$ by full-matrix least-squares techniques with the ShelXL program ${ }^{[25]}$ in Olex $^{2}$ 1.2.1 software package. ${ }^{[27]}$ The non-hydrogen atoms were treated anisotropically, whereas all hydrogen atoms were placed in calculated ideal positions and treated as riding atoms using isotropic displacement parameters 1.2 larger than that of the respective host atoms.

CCDC-1057506 (2), CCDC-1057507 (3), CCDC-1057508 (4), CCDC1057509 (5), CCDC-1057510 (6), CCDC-1057511 (7) and CCDC1057512 (10) contain the supplementary crystallographic data for this paper. These data can be obtained free of charge from the Cambridge Crystallographic Data Centre via www.ccdc.cam.ac.uk/data request/cif.

\section{Computational methods}

Magnetic coupling constants were calculated for complexes 2-5 in their crystal structure geometries ( $\mathrm{C}-\mathrm{H}$ bond lengths normalized to $1.089 \AA$ ) using DFT within the broken symmetry (BS) formalism. ${ }^{[28]}$ The calculations were performed on pairs of metal complexes with four spin sites (two transition metal ions and two radicals). The pairs can be described by the isotropic Heisenberg spin Hamiltonian

$$
\widehat{H}=-2 J_{1}\left(\hat{S}_{\mathrm{MA}} \cdot \hat{S}_{(\mathbf{1}) \mathrm{A}}+\hat{S}_{\mathrm{MB}} \cdot \hat{S}_{(\mathbf{1}) \mathrm{B}}\right)-2 J_{2}\left(\hat{S}_{(\mathbf{1}) \mathrm{A}} \cdot \hat{S}_{(\mathbf{1}) \mathrm{B}}\right),
$$

where $J_{1}$ is the metal-radical coupling constant, $J_{2}$ is the radical $\cdots$ radical coupling constant and $\hat{S}_{\mathrm{i}}$ are appropriate spin operators for the metal (M) and the radical 1. Energies of four different BS states were calculated: $|\uparrow \uparrow \uparrow \uparrow\rangle,|\uparrow \uparrow \downarrow \downarrow\rangle,|\uparrow \downarrow \downarrow \uparrow\rangle$ and $|\uparrow \downarrow \uparrow \downarrow\rangle$, where the order of spin indices is metalradical-radical-metal. The coupling constants $J_{1}$ and $J_{2}$ were then extracted from the calculated energy differences between different states. ${ }^{[29]}$ All BS DFT calculations were performed with the Gaussian 09 program suite ${ }^{[30]}$ using the LC- $\omega$ PBE exchange correlation functional[31] and def-TZVP basis sets. ${ }^{[32]}$ This particular functional was chosen because of its good performance in the description of magnetic coupling constants in a number of paramagnetic systems. ${ }^{[33]}$ 
The ZFS parameters of complexes 3-5 were calculated with multiconfigurational wave function methods. The calculations were performed on a single respective complex in its crystal structure geometry $(\mathrm{C}-\mathrm{H}$ bond lengths normalized to $1.089 \AA$ A). First, a stateaveraged CASSCF calculation was performed on each system. ${ }^{[34]}$ The active space consisted of six orbitals (the five $3 \mathrm{~d}$ orbitals of the metal ion and the SOMO of the radical ligand) and seven, eight or nine electrons for 3, 4, and 5, respectively. This choice, together with the NEVPT2 correction, provides a balanced treatment of different electron correlation effects in these systems. All 198 roots (6 sextets, 66 quartets and 126 doublets) were solved for 3 , all 180 roots ( 15 quintets, 75 triplets and 90 singlets) were solved for $\mathbf{4}$, and all 70 roots (20 quartets and 50 doublets) were solved for $\mathbf{5}$. Scalar relativistic effects were treated by replacing the single electron operator in the CASSCF Hamiltonian by the standard second order Douglas-Kroll-Hess (DKH) operator. ${ }^{[35]}$ SOC effects were then introduced by quasi-degenerate perturbation theory (QDPT) in a basis of the CASSCF solutions using a spin-orbit mean-field operator. ${ }^{[36]}$ Dynamic electron correlation was added by replacing the diagonal elements of the Hamiltonian matrix by ones corrected with NEVPT2 in its strongly contracted form. ${ }^{[37]}$ The ZFS parameters were then extracted from the spin-orbit coupled eigenstates and eigenvalues using the effective Hamiltonian approach. ${ }^{[38]}$ All CASSCF, NEVPT2 and QDPT calculations were performed with the ORCA program. ${ }^{[39]}$ Special defTZVP basis sets re-contracted for scalar relativistic calculations were employed with corresponding auxiliary basis sets. ${ }^{[40]}$

\section{Acknowledgements}

The authors acknowledge the Academy of Finland, the Technology Industries of Finland Centennial Foundation, the University of Jyväskylä, the University of Bordeaux, Région Aquitaine, CNRS, the University of Cyprus and the Cyprus Research Promotion Foundation for generous funding of this research. Laboratory technician Elina Hautakangas is thanked for performing the elemental analyses. Input from Dr. Anssi Peuronen regarding X-ray crystallographic analyses is gratefully acknowledged.

[1] a) I. Ratera, J. Veciana, Chem. Soc. Rev. 2012, 41, 303-349; b) J. S. Miller, Chem. Soc. Rev. 2011, 40, 3266-3296.

[2] A. Caneschi, D. Gatteschi, R. Sessoli, P. Rey, Acc. Chem. Res. 1989 22, 392-398.

[3] a) B. I. Kharisov, M. A. Méndez-Rojas, A. D. Garnovskii, E. P. Ivakhnenko, U. Ortiz-Méndez, J. Coord. Chem. 2002, 55, 745-770. b) C. G. Pierpont, J. K. Kelly in Patai's Chemistry of Functional Groups: Chemistry of Metal Phenolates (Ed: J. Zabicky), Wiley-Blackwell, 2014 pp. 669-698.

[4] a) H. Karoui, F. Le Moigne, O. Ouari, P. Tordo in Stable Radicals: Fundamentals and Applied Aspects of Odd-Electron Compounds (Ed. R. G. Hicks), John Wiley \& Sons, 2010, pp. 173-229; b) V. Ovcharenko in Stable Radicals: Fundamentals and Applied Aspects of Odd-Electron Compounds (Ed.: R. G. Hicks), John Wiley \& Sons, 2010, pp. 461-506.

[5] a) R. G. Hicks in Stable Radicals: Fundamentals and Applied Aspects of Odd-Electron Compounds (Ed.: R. G. Hicks), John Wiley \& Sons, 2010, pp. 317-380. b) K. E. Preuss, Coord. Chem. Rev., DOI:10.1016/..ccr.2014.09.016

[6] a) R. G. Hicks in Stable Radicals: Fundamentals and Applied Aspects of Odd-Electron Compounds (Ed.: R. G. Hicks), John Wiley \& Sons, 2010, pp. 245-279; b) D. J. R. Brook, Comments Inorg. Chem. 2015, 35 $1-17$.

[7] H. M. Blatter, H. Lukaszewski, Tetrahedron Lett. 1968, 2701-2705.
[8] a) P. A. Koutentis, D. Lo Re, Synthesis 2010, 2075-2079; b) C. P Constantinides, P. A. Koutentis, G. Loizou, Org. Biomol. Chem. 2011, 9, 3122-3125; c) A. A. Berezin, C. P. Constantinides, C. Drouza, M. Manoli, P. A. Koutentis, Org. Lett. 2012, 14, 5586-5589; d) A. A. Berezin, C. P. Constantinides, S. I. Mirallai, M. Manoli, L. L. Cao, J. M. Rawson, P. A. Koutentis, Org. Biomol. Chem. 2013, 11, 6780-6795; e) A. A. Berezin, G. Zissimou, C. P. Constantinides, Y. Beldjoudi, J. M. Rawson, P. A. Koutentis, J. Org. Chem. 2013, 79, 314-327.

[9] I. S. Morgan, A. Peuronen, M. M. Hanninen, R. W. Reed, R. Clérac, H M. Tuononen, Inorg. Chem. 2014, 53, 33-35.

[10] J. H. van Vleck The Theory of Electric and Magnetic Susceptibility, Oxford University Press, 1932.

[11] a) B. E. Myers, L. Berger, S. Friedberg, J. Appl. Phys. 1969, 40, 11491151; b) C. J. O'Connor, Prog. Inorg. Chem. 1982, 29, 203-283.

[12] a) I. A. Gass, C. J. Gartshore, D. W. Lupton, B. Moubaraki, A. Nafady, A. M. Bond, J. F. Boas, J. D. Cashion, C. Milsmann, K. Wieghardt, K. S. Murray, Inorg. Chem. 2011, 50, 3052-3064. b) I. A. Gass, S. Tewary, G. Rajaraman, M. Asadi, D. W. Lupton, B. Moubaraki, G. Chastanet, J.-F. Létard, K. S. Murray, Inorg. Chem. 2014, 53, 5055-5066.

[13] a) J. J. Borrás-Almenar, J. M. Clemente-Juan, E. Coronado, B. S. Tsukerblat, Inorg. Chem. 1999, 38, 6081-6088; b) J. J. Borrás-Almenar, J. M. Clemente-Juan, E. Coronado, B. S. Tsukerblat, J. Comput. Chem. 2001, 22, 985-991.

[14] S. Vela, A. Sopena, J. Ribas-Arino, J. J. Novoa, M. Deumal, Chem.-Eur. J. 2014, 20, 7083-7090.

[15] a) E. Ruiz, S. Alvarez, J. Cano, V. Polo, J. Chem. Phys. 2005, 123, 164110; b) C. Adamo, V. Barone, A. Bencini, R. Broer, M. Filatov, N. M. Harrison, F. Illas, J. P. Malrieu, I. de P. R. Moreira, J. Chem. Phys. 2006, 124, 107101; c) E. Ruiz, J. Cano, S. Alvarez, V. Polo, J. Chem. Phys. 2006, 124, 107102.

[16] R. G. Hicks, M. T. Lemaire, L. K. Thompson, T. M. Barclay, J. Am. Chem. Soc. 2000, 122, 8077-8078.

[17] T. M. Barclay, R. G. Hicks, M. T. Lemaire, L. K. Thompson, Inorg Chem. 2001, 40, 5581-5584.

[18] C. Ahlers, M. H. Dickman, Inorg. Chem. 1998, 37, 6337-6340.

[19] N. G. R. Hearns, E. M. Fatila, R. Clérac, M. Jennings, K. E. Preuss, Inorg. Chem. 2008, 47, 10330-10341.

[20] a) C. P. Constantinides, P. A. Koutentis, H. Krassos, J. M. Rawson, A J. Tasiopoulos, J. Org. Chem. 2011, 76, 2798-2806; b) C. P. Constantinides, P. A. Koutentis, J. M. Rawson, Chem.-Eur. J. 2012, 18, 7109-7116; c) C. P. Constantinides, A. A. Berezin, M. Manoli, G. M. Leitus, G. A. Zissimou, M. Bendikov, Chem.-Eur. J. 2014, 20, 53885396.

[21] C. P. Constantinides, P. A. Koutentis, J. M. Rawson, Chem.-Eur. J. 2012, 18, 15433-15438.

[22] F. Izumi, R. Kurosawa, H. Kawamoto, H. Akaiwa, Bull. Chem. Soc. Jpn. 1975, 48, 3188-3192.

[23] a) L. Jovevska, F. Anastasova, V. Aleksić, Synth. Commun. 1996, 26, 279-286; b) J. A. Kitchen, N. G. White, M. Boyd, B. Moubaraki, K. S. Murray, P. D. Boyd, S. Brooker, Inorg. Chem. 2009, 48, 6670-6679.

[24] CrysalisPro program, version 1.171.36.21, Agilent Technologies, Oxford, 2012.

[25] G. M. Sheldrick, Acta Crystallogr., Sect. A: Found. Crystallogr. 2008, 64, 112-122.

[26] L. Palatinus, G. Chapuis, J. Appl. Cryst. 2007, 40, 786-790.

[27] O. V. Dolomanov, L. J. Bourhis, R. J. Gildea, J. A. K. Howard, H. J. Puschmann, J. Appl. Cryst. 2009, 42, 339-341.

[28] a) L. Noodleman, J. Chem. Phys. 1981, 74, 5737-5743; b) G. Jonkers, C. A. Lange, L. Noodleman, E. J. Baerends, Mol. Phys. 1982, 46, 609620 ; c) L. Noodleman, J. G. Jr. Norman, J. H. Osborne, A. Aizman, D. A. Case, J. Am. Chem. Soc. 1985, 107, 3418-3426; d) L. Noodleman, E. R. Davidson, Chem. Phys. 1986, 109, 131-143.

[29] a) D. Dai, M.-H. Whangbo, J. Chem. Phys. 2001, 114, 2887-2893; b) D. Dai, M.-H. Whangbo, J. Chem. Phys. 2003, 118, 29-39; c) I. de P. R Moreira, F. Illas, Phys. Chem. Chem. Phys. 2006, 8, 1645-1659. 
[30] Gaussian 09, Revision D.01, M. J. Frisch, G. W. Trucks, H. B. Schlegel, G. E. Scuseria, M. A. Robb, J. R. Cheeseman, G. Scalmani, V. Barone B. Mennucci, G. A. Petersson, H. Nakatsuji, M. Caricato, X. Li, H. P. Hratchian, A. F. Izmaylov, J. Bloino, G. Zheng, J. L. Sonnenberg, M. Hada, M. Ehara, K. Toyota, R. Fukuda, J. Hasegawa, M. Ishida, T. Nakajima, Y. Honda, O. Kitao, H. Nakai, T. Vreven, J. A. Montgomery, Jr., J. E. Peralta, F. Ogliaro, M. Bearpark, J. J. Heyd, E. Brothers, K. N. Kudin, V. N. Staroverov, R. Kobayashi, J. Normand, K. Raghavachari, A. Rendell, J. C. Burant, S. S. lyengar, J. Tomasi, M. Cossi, N. Rega, J. M. Millam, M. Klene, J. E. Knox, J. B. Cross, V. Bakken, C. Adamo, J. Jaramillo, R. Gomperts, R. E. Stratmann, O. Yazyev, A. J. Austin, R. Cammi, C. Pomelli, J. W. Ochterski, R. L. Martin, K. Morokuma, V. G. Zakrzewski, G. A. Voth, P. Salvador, J. J. Dannenberg, S. Dapprich, A D. Daniels, Ö. Farkas, J. B. Foresman, J. V. Ortiz, J. Cioslowski, and D. J. Fox, Gaussian, Inc., Wallingford CT, 2009.

[31] O. A. Vydrov, G. E. Scuseria, J. Chem. Phys. 2006, 125, 234109.

[32] A. Schaefer, C. Huber, R. Ahlrichs, J. Chem. Phys. 1994, 100, 5829 5835.

[33] a) P. Rivero, I. de P. R. Moreira, F. Illas, G. E. Scuseria, J. Chem. Phys. 2008, 129, 184110; b) J. Peralta, J. I. Melo, J. Chem. Theory Comput.
2010, 6, 1894-1899; c) E. Ruiz, J. Comp. Chem. 2011, 32, 1998-2004; d) T. Saito, A. Ito, T. Watanabe, T. Kawakami, M. Okumura, K. Yamaguchi, Chem. Phys. Lett. 2012, 542, 19-25; e) R. Costa, R. Valero, D. R. Mañeru, I. de P. R. Moreira, F. Illas, J. Chem. Theory. Comput. 2015, 11, 1006-1019.

[34] B. O. Roos, in Advances in Chemical Physics, Ab Initio Methods in Quantum Chemistry-II, Vol. 69 (Ed.: K. P. Lawley), Wiley, 1987, pp. 399-455.

[35] M. Douglas, N. M. Kroll, Ann. Phys. 1974, 82, 89-155.

[36] F. Neese, E. I. Solomon, Inorg. Chem. 1998, 37, 6568-6582.

[37] a) C. Angeli, R. Cimiraglia, S. Evangelisti, T. Leininger, J.-P. Malrieu, J. Chem. Phys. 2001, 114, 10252-10264; b) C. Angeli, C. Cimiraglia, J.-P. Malrieu, Chem. Phys. Lett. 2001, 350, 297-305; c) C. Angeli, C. Cimiraglia, J.-P. Malrieu, J. Chem. Phys. 2002, 117, 9138-9153.

[38] R. Maurice, R. Bastardis, C. de Graaf, N. Suaud, T. Mallah, N. Guihéry, J. Chem. Theory Comput. 2009, 5, 2977-2984.

[39] F. Neese, Wiley Interdiscip. Rev.: Comput. Mol. Sci. 2012, 2, 73-78.

[40] D. A. Pantazis, X. Y. Chen, C. R. Landis, F. Neese., J. Chem. Theory. Comput. 2008, 4, 908-919. 